\title{
In vitro integrity of implant external hexagon after application of surgical placement torque simulating implant locking
}

\begin{abstract}
Letícia Resende Davi(a)
Alexsander Luiz Golin (b)

Sérgio Rocha Bernardes(c)

Cleudmar Amaral de Araújo(d)

Flávio Domingues Neves ${ }^{(\mathrm{e})}$
\end{abstract}

(a) Master of Science; (e) Associate Professor - Department of Occlusion, Fixed Prosthesis and Dental Materials, School of Dentistry,

Federal University of Uberlândia.

(b) Master of Science, Department of Mechanical Engineering, School of Mechanical Engineering, Pontifical Catholic University of Curitiba.

(c) Professor, Scientific Department, Latin American Institute of Dental Research and Education (ILAPEO).

(d) Associate Professor, Department of Projects and Mechanical Systems, School of Mechanical Engineering, Federal University of Uberlândia.

\begin{abstract}
The aim of this study was to evaluate the integrity of the external hexagon of an implant system with internal and external hexagons but with prosthetic connection through the external hexagon (Internal Torque, IT) in comparison with that of an implant system with external hexagon with mount (External Hexagon, EH). A device was made to measure the rotational freedom angles between implant and abutment hexagons in 10 implants from each group after the application of surgical placement torques of 45, 60 and $80 \mathrm{Ncm}$ simulating implant locking. The distances between the vertices of the external hexagon were also obtained. Rotational freedom data were subjected to ANOVA and Tukey's test $(P<.05)$ showing no significant difference between the angles of the intact implants $\left(\mathrm{EH}-3.31 \pm 0.41^{\circ}\right.$ and IT $\left.-3.30 \pm 0.17^{\circ}\right)$ and after application of a $45 \mathrm{Ncm}$ torque $\left(\mathrm{EH}-3.27 \pm 0.38^{\circ}\right.$ and $\left.\mathrm{IT}-3.31 \pm 0.22^{\circ}\right)$. However, after application of a $60 \mathrm{Ncm}$ torque there were significant differences $\left(\mathrm{IT}-3.40 \pm 0.20^{\circ}\right.$ and $\left.\mathrm{EH}-4.03 \pm 0.54^{\circ}\right)$. After application of a $80 \mathrm{Ncm}$ torque, the IT implant presented values of $3.39 \pm 0.21^{\circ}$ whereas the EH did not support the torque, suffering deformation of its external hexagon. Within the limits of this study, it can be concluded that the IT implant system may be preferable in clinical situations where implant placement within a certain bone density could generate torques higher than $60 \mathrm{Ncm}$.
\end{abstract}

Descriptors: Biomechanics; Dental implants; Torque; Dental prosthesis.
Corresponding author:

Flávio Domingues Neves

Av. Pará, 1720 - Bloco 2B, Sala 2B01

Uberlândia - Minas Gerais - Brazil

CEP: 38400-902

E-mail:neves@triang.com.br

Received for publication on Oct 23, 2006

Accepted for publication on Jun 08, 2007 


\section{Introduction}

Over the last few decades, the use of dental implants in partially edentulous patients, including single tooth replacements, has revolutionized esthetic and functional rehabilitation. Brånemark et al. ${ }^{1}$ (1977) reported the principles of osseointegration of titanium implants in bone tissue and their clinical application in rehabilitating edentulous patients, thus reestablishing masticatory function.

The initial purpose of external hexagon implants was to transmit torque during surgical placement. Afterwards, the external hexagon was also shown to work as an antirotational mechanism and to orient the abutment in single tooth prostheses. Although these implants have been the ones most commonly used, and are designed by several companies all over the world, possible fatigue or overload failures could occur due to different manufacturing tolerances. The biomechanical complications reported are loosening or fracturing of the abutment and prostheses screws. ${ }^{2-11}$ Therefore, the external hexagon connection continues to be comprehensively studied with the aim of improving the dimensional machining tolerances of the components, ${ }^{12}$ and making this screwed junction more stable. ${ }^{3-5,7,9}$

The rotational freedom between implant and abutment depends on the hexagon dimensions that are in connection. ${ }^{3-5,9,10}$ These dimensions can be compromised during surgical placement, depending on the torque applied, and after connection of the prosthesis, when the masticatory load could generate micromovements and deform the implant hexagon. ${ }^{5}$

In the last few years, the surgical process was changed to a single stage, with immediate loading using the prosthesis connected to the implant..$^{13,14}$ The advantages of immediate loading include less chair time and simplification of the dental replacement process. ${ }^{15}$ However, implants submitted to immediate loading need primary stability to prevent failure of osseointegration. ${ }^{13-15}$ This primary stability is obtained by attaching the implant to the bone and is normally checked by the value of the torque applied.

Recently, some internal implant connections have appeared on the market, which are able to receive higher torques during surgical placement, with effective screw joint stability. ${ }^{8}$ Sometimes these internal geometries make the prosthetic procedure more difficult and reduce the number of implant manufacturing companies with compatible systems.

Considering the hypothesis that implant systems with external hexagon devices for prosthesis connection and internal torque can improve the stability of the system, it could also speed up and facilitate surgical placement. Therefore, this in vitro study evaluated the integrity of the external hexagon of an implant system with internal and external hexagons, but with prosthetic connection through the external hexagon, in comparison with that of a conventional external hexagon implant with mount, by means of different levels of surgical placement torque applied simulating implant locking.

\section{Material and Methods}

Ten implants with external hexagon (Titamax Pores with mount - EH; 3.75 mm-wide, Neodent Implante Osteointegrável, Curitiba, PR, Brazil) and ten implants with internal and external hexagons but with prosthetic connection through the external hexagon (Cortical Titamax - IT; 3.75 mm-wide, Neodent Implante Osteointegrável, Curitiba, PR, Brazil), both with $4.1 \mathrm{~mm}$-wide platform size, were used in this study.

An experimental device was designed and made to apply surgical placement torque on the dental implants and to measure rotational freedom angles between the abutment and the implant. The device consists of an apparatus to lock the implant using two side screws with nuts, a graduated scale with precision of $0.025^{\circ}$, a rod to measure the rotational freedom angle, and a steel device fitted to the abutment under pressure, as shown in Figure 1.

Each implant was placed in the device and fitted to the abutment and the rod, without requiring the abutment screw. Initially, the rotational freedom angle readings were taken with the intact implants positioned in the device.

The graduated scale can be moved to locate the initial point of the rotational angle reading at the reference mark of 0 degree, and is then fixed by a lateral screw. This initial point is marked when 




Figure 1 - Experimental device used to measure rotational freedom angles.

one of the vertices of the implant external hexagon touches one of the sides of the abutment internal hexagon. To obtain the initial point, the rod was turned by hand in a counterclockwise direction until it encountered slight resistance from the connection. Next, the rod was moved in a clockwise direction, again until there was slight resistance from the connection. At this moment, the values of the angles read on the scale were recorded. In order to minimize the errors in the measurements, each reading was repeated twice by two operators and the mean average of the four measurements was obtained. The operators were trained by measuring together two implants of each type and by analyzing how to obtain the angles on the graduated scale.

The implants were submitted to three levels of surgical placement torques: 45,60 and $80 \mathrm{Ncm}$. The torque of $45 \mathrm{Ncm}$ was applied in the groups with the aid of an electronic torque controller handpiece (DEA 020, Brånemark System, Nobelpharma AB, Gothenburg, Sweden) at low-speed rotation. The values of the rotational freedom angles were taken in a similar manner to that in which the rotational freedom values for the intact implants were record- ed. After the readings, the same analysis was made, successively, for the torques of 60 and $80 \mathrm{Ncm}$, with the aid of a surgical torquemeter ratchet (Neodent Implante Osteointegrável, Curitiba, PR, Brazil).

The distances between the vertices of the external hexagon were also used to evaluate the integrity of the external hexagon of the two groups of implants. These measurements were obtained for all intact implants, before any mechanical contact, and after each torque applied. Two operators measured the three distances between the vertices of each external hexagon and the mean value was determined. The measurements were carried out using an optical microscope (Carl Zeiss, Jena, TH, Germany), with a 20 times magnification. Each implant was placed in a device with a handle to turn the implant and place the vertex of the hexagon at the initial point of measurement.

The rotational freedom angles and the distances between the vertices of the external hexagons of the implants after different levels of torque were submitted to statistical analysis by ANOVA and Tukey's test $(P<.05)$, with the aid of the statistical program SPSS 12.0 (SPSS Inc., Chicago, IL, USA). 


\section{Results}

Mean values of rotational freedom angles are presented in Table 1. Statistical analysis by ANOVA and Tukey's test showed that there was no significant difference between the angles of the intact $\mathrm{EH}$ and IT implants and after application of the torque of $45 \mathrm{Ncm}$. After application of the torque of $60 \mathrm{Ncm}$, significant difference $(P<.05)$ was found between the EH and IT systems. After application of the torque of $80 \mathrm{Ncm}$, the vertices of the $\mathrm{EH}$ im-

Table 1 - Mean \pm SD values of the rotational freedom angles ( $\left.{ }^{\circ}\right)$ for the $\mathrm{EH}$ and IT implants.

\begin{tabular}{c|c|c}
\hline Torque & EH Implants* & IT Implants \\
\hline 0 & $3.308 \pm 0.406^{\circ} \mathrm{A}$ & $3.298 \pm 0.168^{\circ} \mathrm{A}$ \\
\hline $45 \mathrm{Ncm}$ & $3.274 \pm 0.380^{\circ} \mathrm{A}$ & $3.309 \pm 0.220^{\circ} \mathrm{A}$ \\
\hline $60 \mathrm{Ncm}$ & $4.029 \pm 0.544^{\circ} \mathrm{B}$ & $3.405 \pm 0.197^{\circ} \mathrm{A}$ \\
\hline $80 \mathrm{Ncm}$ & - & $3.387 \pm 0.215^{\circ} \mathrm{A}$ \\
\hline
\end{tabular}

*After application of the torque of $80 \mathrm{Ncm}$ the vertices of the $\mathrm{EH}$ implants became deformed, annulling their antirotational effect. Groups that are significantly different $(P<.05)$ are marked with different letters. plants became deformed, annulling their antirotational effect, and making it impossible to measure the respective angles (Figure 2).

The mean distances between the hexagon vertices of the samples measured in the microscope, under different levels of torque, are shown in Graph 1.

The statistical analysis showed that there was no significant difference between the distances between the vertices of intact EH and IT implants and after application of the torques of 45 and $60 \mathrm{Ncm}$. After application of the torque of $80 \mathrm{Ncm}$, the vertices of the EH implants became deformed, and Tukey's test showed significant difference between the values for the EH and IT implants (Table 2).

\section{Discussion}

Dental implants are placed by means of external or internal connections and by the application of a certain level of torque. The connection could therefore become deformed and result in biomechanical complications over time. The Internal Torque implant that requires an implant driver to connect
After $45 \mathrm{Ncm}$
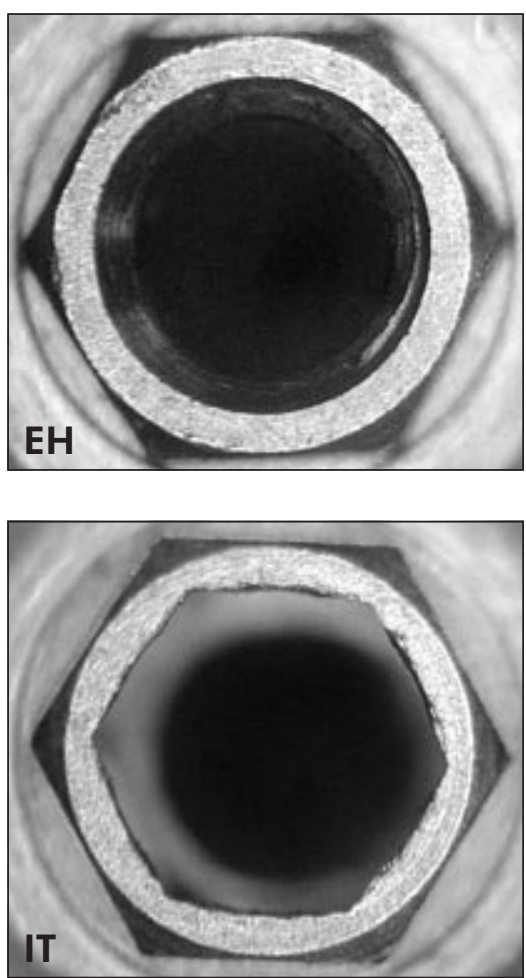

After $60 \mathrm{Ncm}$
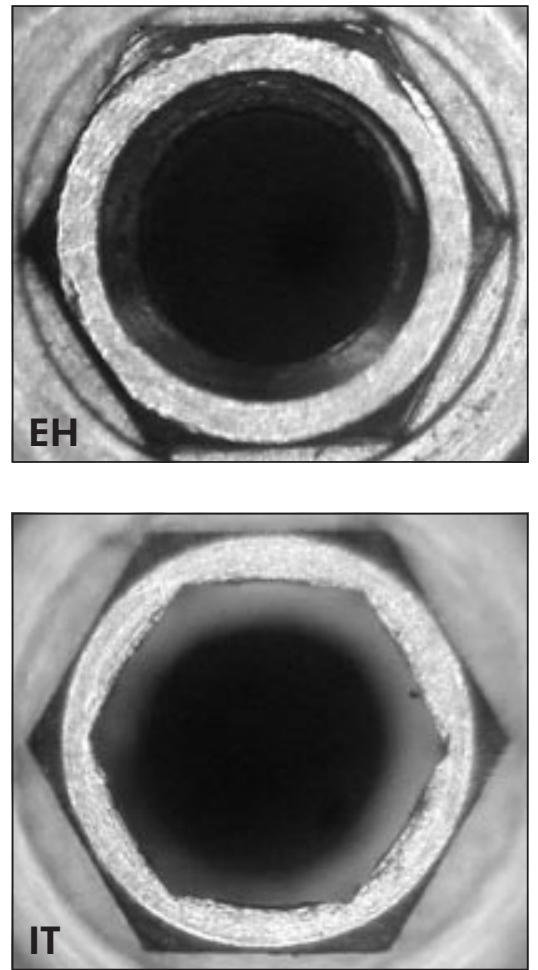

After $80 \mathrm{Ncm}$
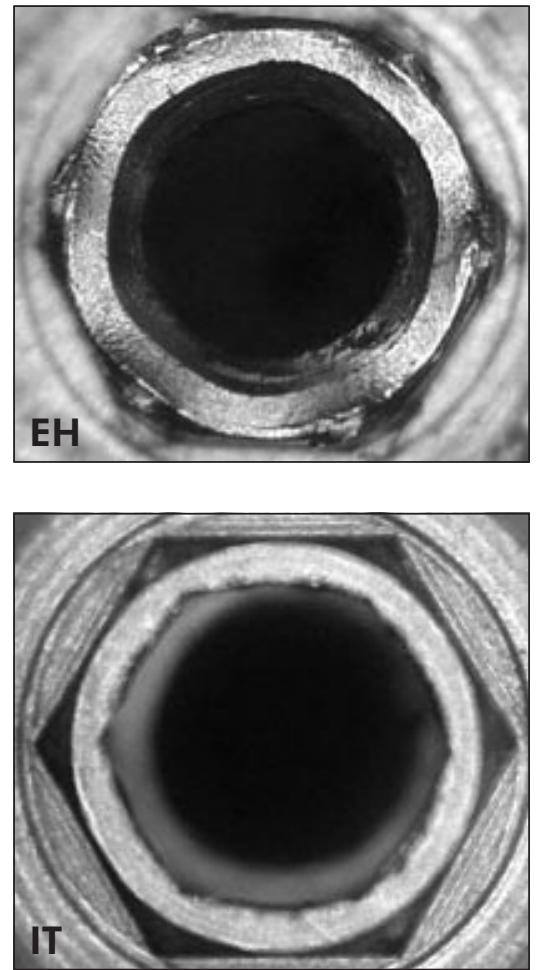

Figure 2 - EH and IT implants after application of 45, 60 and $80 \mathrm{Ncm}$ torques. 




Graph 1 - Mean distances between the hexagon vertices of the implant hexagons under different levels of torque $(P<.05)$.

Table 2 - Mean \pm SD values of the distances $(\mathrm{mm})$ between the vertices of the EH and IT implants.

\begin{tabular}{c|c|c}
\hline \multicolumn{1}{c|}{ Implants } & Torque & Mean \pm SD \\
\hline \multirow{4}{*}{$\begin{array}{c}\text { External } \\
\text { Hexagon }\end{array}$} & 0 & $3.084 \pm 0.009 \mathrm{~mm} \mathrm{~A}$ \\
\cline { 2 - 3 } & $45 \mathrm{Ncm}$ & $3.078 \pm 0.015 \mathrm{~mm} \mathrm{~A}$ \\
\cline { 2 - 3 } & $60 \mathrm{Ncm}$ & $3.063 \pm 0.020 \mathrm{~mm} \mathrm{~A}$ \\
\cline { 2 - 3 } & $80 \mathrm{Ncm}$ & $2.861 \pm 0.073 \mathrm{~mm} \mathrm{~B}$ \\
\hline \multirow{4}{*}{ Internal Torque } & 0 & $3.088 \pm 0.006 \mathrm{~mm} \mathrm{~A}$ \\
\cline { 2 - 3 } & $45 \mathrm{Ncm}$ & $3.087 \pm 0.006 \mathrm{~mm} \mathrm{~A}$ \\
\cline { 2 - 3 } & $60 \mathrm{Ncm}$ & $3.074 \pm 0.009 \mathrm{~mm} \mathrm{~A}$ \\
\cline { 2 - 3 } & $80 \mathrm{Ncm}$ & $3.073 \pm 0.009 \mathrm{~mm} \mathrm{~A}$ \\
\hline
\end{tabular}

Values with different letters are significantly different $(P<.05)$.

it to the internal hexagon and transmit torque for implant placement showed improved mechanical properties, confirming the hypothesis proposed in this study.

The fragility of the external hexagon of some systems can compromise the future dental prosthesis if deformation of the hexagon vertices occurs due to the torque applied in the implant mount when the implant is placed. In these situations, the angles of rotational freedom between abutment and implant are increased, and this is especially critical in single prostheses. ${ }^{5}$ Greater rotation at the interface implant-abutment transfers stress to the implant components and to the bone, which could lead to screw loosening or fracturing, microfractures of bone, and loss of osseointegration. , $^{2,10}$

The integrity of the external hexagon was evaluated in all implants before torque application, and both the rotational freedom measurements and the distances of the hexagon vertices showed no significant differences between values for the EH and IT implants, because of the same machining tolerances. This result proves that the industrial production of the analyzed implants was standardized, and eliminates the possibility of initial failings.

Considering the technique of implant placement with immediate loading, there is a single-stage surgical procedure that has the advantage of immediate rehabilitation by means of fixed prostheses. In these cases, primary stability into the bone is very important, and this depends on the value of the torque applied during surgical placement. ${ }^{11,16,17}$ Misch $^{14}$ (2004) established a minimum torque of $30 \mathrm{Ncm}$ so that the implants could obtain primary stability for immediate loading. In other words, to be considered stable, the implant could not turn or show any mobility after the torque of $30 \mathrm{Ncm}$ was reached. Bahat $^{18}$ (2000) evaluated the long-term success of implants placed in the posterior area of the maxilla, under a condition of primary stability with a minimum torque of $40 \mathrm{Ncm}$. Both authors referred to a minimum torque for immediate loading, but there was no evidence about the maximum torque that could be applied on the implants without deforming the external hexagon.

Until the year of 1995, the electronic torque controllers available from Nobelpharma for implant placement were DEC 100 and DEA 020 (Nobelpharma AB, Gothenburg, Sweden), which allowed a maximum torque of $45 \mathrm{Ncm}$. They were used in the majority of the long-term studies published in the literature. ${ }^{1,2,6}$ Some of the implants, however, still required the manual torque wrench (DIA 250; Nobelpharma AB, Gothenburg, Sweden) to complete the implant seating, with uncontrolled torque but higher than $45 \mathrm{Ncm}$. Degidi, Piattellii' ${ }^{16}$ (2005), in a study with 702 implants, reported torques higher than $76 \mathrm{Ncm}$. In vitro studies showed that placement torques above $100 \mathrm{Ncm}$ increase the primary stability of different implant systems by reducing 
the amount of micromotion. ${ }^{19}$ Moreover, local bone density varies according to each surgical site, and the same drilling protocol could lead the implant to receive different levels of torque during placement until complete seating. ${ }^{20}$ The surgical torquemeter ratchets available in the market are graduated with the minimum torque $(32 \mathrm{Ncm})$ (28839 - Nobel Biocare, TMEC - SIN Sistema de Implante) and allow higher measurements, achieving $80 \mathrm{Ncm}$ (104027 - Neodent Implante Osteointegrável, 401000 - Conexão Sistemas de Prótese).

With the application of surgical placement torques it was possible to evaluate the deformations of the conventional external hexagon vertices and consequent changes in the system rotation. Different levels of torque were applied to the samples and the accumulative effects, although having small influence, were the same for the IT and EH implants. Thus, the load effect and possible deformation were equal for the implants. The torque of $60 \mathrm{Ncm}$ caused a significant increase of the rotational freedom of the EH implants and the torque of $80 \mathrm{Ncm}$ deformed the hexagon completely. Such deformations were not found in the IT implants because it uses the internal hexagon to transmit the torque for implant placement.

The junction between the abutment and the external hexagon of the EH and IT implants needs to be reliable for appropriate functioning and stability of implant-supported prostheses. ${ }^{8}$ For this to occur, the differences between the dimensions of the abutment hexagons and the respective implant must be minimal to favor the passive fit of the components and prevent stress from emerging in the screw due to rotational misfit. ${ }^{21}$

According to Binon ${ }^{4}$ (1996), joint stiffness and

\section{References}

1. Brånemark PI, Hansson $\mathrm{BO}$, Adell R, Breine U, Lindström J, Hallén $\mathrm{O}$ et al. Osseointegrated implants in the treatment of the edentulous jaw: experience from a 10-year period. Scand J Plast Reconstr Surg. 1977;16(Suppl):1-132.

2. Adell R, Lekholm U, Rockler B, Brånemark PI. A 15-year study of osseointegrated implants in the treatment of the edentulous jaw. Int J Oral Surg. 1981;10(6):387-416. preload are compromised when the rotational angles exceed 5 degrees, leading to failure of the screwed junction by screw loosening and movement of the abutment. In the present study, it was observed that the EH and IT implants maintained angles of rotational freedom below 5 degrees under the different levels of torque. But under the torque of $80 \mathrm{Ncm}$, it was impossible to measure the angles of the $\mathrm{EH}$ implants, due to deformation of the external hexagon.

It is important to emphasize that the $\mathrm{EH}$ implants may be indicated for cases where the applied torque does not exceed $60 \mathrm{Ncm}$. In this case, predictability may be achieved for implant-supported prostheses.

\section{Conclusions}

According to the methodology used in this study and based on the data analysis, it was possible to conclude that:

- Before and after application of a torque of $45 \mathrm{Ncm}$, the IT and EH implants presented similar rotational freedom. After application of a torque of $60 \mathrm{Ncm}$, although the IT implant obtained statistically better results, the EH implants did not present rotational freedom over 5 degrees, which is suggested as optimal for screw joint stability, justifying the clinical success of these implants.

- The use of the IT implant may be preferable in clinical situations where implant placement within a certain bone density could generate torques higher than $60 \mathrm{Ncm}$.

\section{Acknowledgements}

The authors would like to acknowledge the support of Neodent Implante Osteointegrável, Curitiba, PR, Brazil, for their contribution to this work.

3. Binon PP. Evaluation of machining accuracy and consistency of selected implants, standard abutments, and laboratory analogs. Int J Prosthodont. 1995;8(2):162-78.

4. Binon PP. The effect of implant/abutment hexagonal misfit on screw joint stability. Int J Prosthodont. 1996;9(2):149-60.

5. Binon PP, McHugh MJ. The effect of eliminating implant/ abutment rotational misfit on screw joint stability. Int J Prosthodont. 1996;9(6):511-9. 
6. Haas R, Mensdorff-Pouilly N, Mailath G, Watzek G. Brånemark single tooth implants: a preliminary report of $76 \mathrm{im}$ plants. J Prosthet Dent. 1995;73(3):274-9.

7. Lang LA, Wang R-F, May KB. The influence of abutment screw tightening on screw joint configuration. J Prosthet Dent. 2002;87(1):74-9.

8. Merz BR, Hunenbart S, Belser UC. Mechanics of the implant-abutment connection: an 8-degree taper compared to a butt joint connection. Int J Oral Maxillofac Implants. 2000;15(4):519-26.

9. Vigolo P, Majzoub Z, Cordioli G. Measurement of the dimensions and abutment rotational freedom of gold-machined $3 \mathrm{i}$ UCLA-type abutments in the as-received condition, after casting with a noble metal alloy and porcelain firing. J Prosthet Dent. 2000;84(5):548-53.

10. Vigolo P, Fonzi F, Majzoub Z, Cordioli G. An in vitro evaluation of ZiReal abutments with hexagonal connection: in original state and following abutment preparation. Int J Oral Maxillofac Implants. 2005;20(1):108-14.

11. Wicks RA, deRijk WG, Windeler AS. An evaluation of fit in osseointegrated implant components using torque/turn analysis. J Prosthodont. 1994;3(4):206-12.

12. Schulte JK. External hex manufacturing tolerances of six implant systems: a pilot study. Implant Dent. 1994;3(1):51-3.

13. Gapski R, Wang HL, Mascarenhas P, Lang NP. Critical review of immediate implant loading. Clin Oral Implants Res. 2003;14(5):515-27.

14. Misch CM. Immediate loading of definitive implants in the edentulous mandible using a fixed provisional prosthesis: the denture conversion technique. J Oral Maxillofac Surg. 2004;62(9 Suppl 2):106-15.

15. Cunha HA, Francischone CE, Nary Filho H, Oliveira RCG. A comparison between cutting torque and resonance frequency in the assessment of primary stability and final torque capacity of standard and TiUnite single-tooth implants under immediate loading. Int J Oral Maxillofac Implants. 2004;19(4):57885.

16. Degidi M, Piattelli A. Comparative analysis study of 702 dental implants subjected to immediate functional loading and immediate nonfunctional loading to traditional healing periods with a follow-up of up to 24 months. Int J Oral Maxillofac Implants. 2005;20(1):99-107.

17. Lioubavina-Hack N, Lang NP, Karring T. Significance of primary stability for osseointegration of dental implants. Clin Oral Implants Res. 2006;17(3):244-50.

18. Bahat $\mathrm{O}$. Brånemark system implants in the posterior maxilla: clinical study of 660 implants followed for 5 to 12 years. Int J Oral Maxillofac Implants. 2000;15(5):646-53.

19. Wang HL, Ormianer Z, Palti A, Perel ML, Trisi P, Sammartino G. Consensus conference on immediate loading: the single tooth and partial edentulous areas. Implant Dent. 2006;15(4):324-33.

20. Johansson P, Strid KG. Assessment of bone quality from cutting resistance during implant surgery. Int J Oral Maxillofac Implants. 1994;9(3):279-88.

21. Ma T, Nicholls JI, Rubenstein JE. Tolerance measurements of various implant components. Int J Oral Maxillofac Implants. 1997;12(3):371-5. 